\title{
Left atrial appendage exclusion: An alternative to anticoagulation in nonvalvular atrial fibrillation
}

\author{
Kareem Bedeir, MBChB, MS, ${ }^{a}$ David R. Holmes, MD, ${ }^{b}$ James L. Cox, MD, ${ }^{c}$ and \\ Basel Ramlawi, MD, MSc ${ }^{\mathrm{d}}$
}

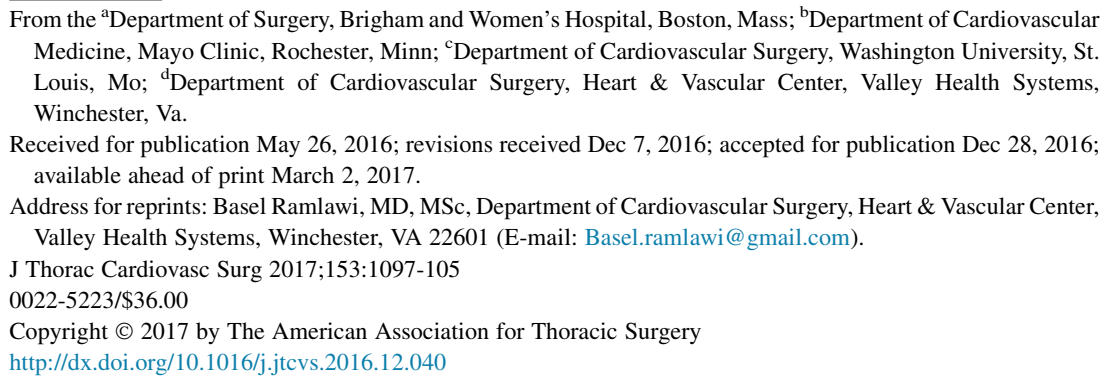

Patients with atrial fibrillation (AF) are 5 times more likely to have a stroke than individuals in sinus rhythm, and 1 in every 5 strokes is secondary to AF. ${ }^{1-3}$ Unfortunately, AFrelated thrombo-emboli are larger and result in ischemic strokes that are more devastating than those secondary to carotid artery disease or other etiologies. ${ }^{4,5}$ Lifelong oral anticoagulation with warfarin has been the guidelinebased therapy to reduce the risk of AF-related ischemic strokes in patients with a $\mathrm{CHA}_{2} \mathrm{DS}_{2}$-VASc (congestive heart failure, hypertension, age $>75$ and diabetes mellitus, previous history of stroke or transient ischemic attack, vascular disease, age 65-74 years, and female sex category) score $\geq 2$. Anticoagulation (AC), however, inherently predisposes to bleeding, including hemorrhagic stokes. Moreover, a significant percentage of patients with AF have relative or absolute contraindications to AC. Even those who can take it do not necessarily experience maximum anticoagulant protection. Despite demonstrating warfarin's benefit in preventing approximately one-half of AF-related strokes, the target international normalized ratio (INR) is achieved in only approximately $60 \%$ of patients despite best practices in dosing and monitoring. ${ }^{6,7} \mathrm{~A}$ recent registry reported that among patients on warfarin for AF, only $26 \%$ were found to have a stable INR within therapeutic range. ${ }^{8}$ The 4 major randomized controlled trials (RCTs) for nonvitamin $\mathrm{K}$ oral anticoagulants (NOACs) have shown the time in therapeutic range (TTR) in the warfarin-treated arms to range from $55 \%$ to $68 \%$ despite optimal dosing and INR monitoring. ${ }^{9}$ In their meta-analysis of the 4 RCTs comparing NOACs with warfarin, Ruff et $\mathrm{al}^{10}$ found NOACs to be superior to warfarin in reducing intracranial bleeding, but not bleeding elsewhere. Like warfarin, NOACs still subject the patient to an above-baseline predisposition to bleeding. They also both subject the patient to lifelong therapy, and despite NOACs eliminating the need for frequent blood tests, dabigatran and apixaban replace the daily warfarin dosing with a twice-daily dosing follow-up.

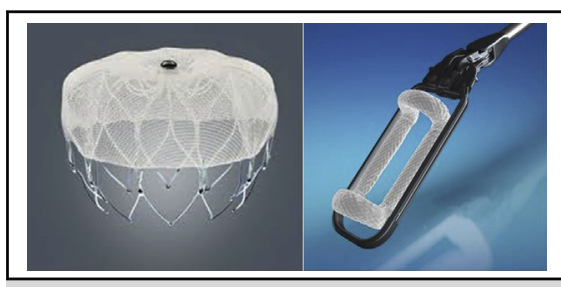

The Watchman endocardial left atrial occlusion device (left) and the Atriclip epicardial left atrial occlusion device (right).

\section{Central Message}

This article reviews the evidence behind the options for stroke risk reduction in patients who cannot have or do not want AC.

\section{Perspective}

Despite the advent of new anticoagulants bleeding continues to be an inherent risk of anticoagulation (AC). There is a need for an alternative to $\mathrm{AC}$ in patients with atrial fibrillation who cannot have or do not want $\mathrm{AC}$.

See Editorial Commentary page 1106

regimen. Finally, approximately $20 \%$ to $25 \%$ of patients on NOACs have discontinued the agent at 2 years of

These shortcomings of anticoagulation triggered a search for alternatives. If thrombi are identified in the left heart of patients with nonvalvular AF-related strokes, they are in the left atrial appendage (LAA) $90 \%$ of the time. ${ }^{11}$ This observation led to an increased interest in closing the LAA mechanically as a potential means of reducing the stroke rate in patients with nonvalvular AF. Successful LAA occlusion can potentially provide patients who cannot tolerate OAC therapy a means of stroke risk reduction, and to spare those who can receive OAC the potential hazards, inconveniences and costs of lifelong anticoagulation. In this review, we discuss techniques and devices aimed at LAA exclusion.

\section{LAA OCCLUSION OR EXCISION}

The first known attempt at occluding or excising the LAA to prevent stroke was reported in 1949 and the outcomes were dismal. ${ }^{12}$ More than 40 years later, Johnson et al ${ }^{13}$ revived interest in excluding what they called "...our most lethal human attachment" (the LAA) from the systemic circulation. Johnson et al ${ }^{13}$ excised the LAA in 437 
patients undergoing cardiac surgery with no increased morbidity or mortality. Despite demonstrating the safety of LAA excision, the efficacy of eliminating the LAA in reducing stroke was not well documented. In the early 2000s, Garcia-Fernandez et al ${ }^{14}$ demonstrated a therapeutic benefit of LAA occlusion but also noted that an incomplete occlusion was detrimental because the residual was thrombogenic. In their retrospective report on patients undergoing mitral valve replacement, they found that leaving the LAA intact was an independent predictor of stroke with a 6.7-fold increased risk, whereas incomplete closure of the LAA increased the risk of stroke by 11.9 -fold. Although the benefits of successfully closing the LAA could not always be reproduced by other investigators, the detrimental consequences of incomplete LAA closure were consistent. ${ }^{15,16}$ Because at that time only approximately $60 \%$ of the LAAs could be closed completely, $40 \%$ of the patients were left with a higher stroke risk than those with an intact LAA. ${ }^{17,18}$ The inability to attain complete LAA closure not only increased the stroke risk but it also precluded an accurate determination of the relationship between LAA occlusion and stroke reduction. However, in 2006, the American College of Cardiology and the American Heart Association (ACC/AHA) recommended exclusion of the LAA surgically during surgical ablation of AF or mitral valve surgery. ${ }^{19}$ Nevertheless, controversy persisted regarding the potential value versus the potential harm of occluding the LAA for stroke in patients with nonvalvular $\mathrm{AF}^{20}$

Approximately 110 publications discussed the LAA over the 30 years from 1960 to 1990 . Interestingly, more than 1000 publications exist discussing the LAA from 2000 to date. ${ }^{21}$ Unfortunately, this exponential increased interest in the LAA was not translated into well-powered RCTs except recently. The literature is abundant in singleinstitution pilot studies and case series, but only 1 adequately powered RCT was completed. In 2014, results from the intermediate to late follow-up of this RCT have, for the first time, provided objective evidence for LAA exclusion as an alternative to $\mathrm{AC}$ in patients with $\mathrm{AF}^{22}$

\section{ENDOCARDIAL LAA OCCLUSION DEVICES}

The first device designed specifically to close the LAA mechanically was the PLAATO device (Ev3; Plymouth, Minn) that consisted of a self-expanding nitinol frame covered by an impermeable polytetrafluoroethylene membrane (Figure 1). High-risk patients with AF who were not candidates for warfarin therapy showed an acceptable safety profile and a complete LAA occlusion rate approaching $98 \%$ with a reduction of stroke risk ranging from $42 \%$ to $65 \%$ compared with their estimated risk based on the $\mathrm{CHADS}_{2}$ (congestive heart failure, hypertension, age $=75$ years, diabetes mellitus, stroke [doubled]) scoring system. $^{23-25}$ In 2007, Atritech (Plymouth, Minn) acquired the PLAATO intellectual property from Ev3, stopped production of the PLAATO, and developed the Watchman device.

\section{The Watchman}

The Watchman device (Boston Scientific, Maple Grove, Minn) is a self-expanding nitinol-based device with distal fixation barbs and a permeable polyester fabric (Figure 1). The Watchman was evaluated in the PROTECT-AF clinical trial that prospectively randomized (2:1) 707 patients with nonvalvular $\mathrm{AF}\left(\mathrm{CHADS}_{2}\right.$ score $\left.\geq 1\right)$ to receive either the Watchman device or warfarin therapy. Rates of successful Watchman implantation and complete LAA occlusion were $91 \%$ and $88 \%$, respectively. Warfarin was also administered to the Watchman group but it was stopped when transesophageal echocardiography (TEE) documented sealing of the LAA with either no residual leak or a leak $\leq 5 \mathrm{~mm}$. At 6 weeks, $86 \%$ of the Watchman group was able to stop warfarin, and $92 \%$ had stopped warfarin at 6 months. After 5 years of follow-up, the primary efficacy endpoint (decrease in stroke, systemic thromboembolism, and cardiovascular death) was $3 \%$ annually with the
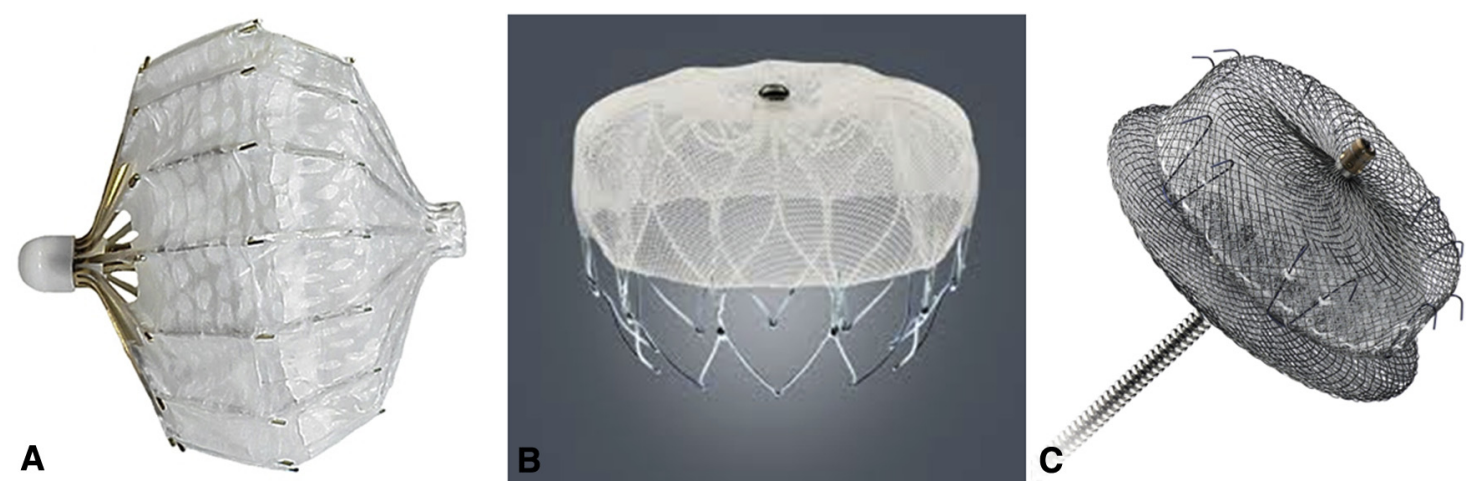

FIGURE 1. Endocardial left atrial appendage occluding devices. A, The PLAATO device. B, The Watchman. C, The Amplatzer cardiac plug. 
Watchman device and $4.3 \%$ in the warfarin group, a $99.9 \%$ probability of noninferiority of the Watchman compared with warfarin therapy. ${ }^{26,27}$

Despite demonstrating efficacy, the Watchman group demonstrated a significantly higher incidence of safety events. The primary safety event rate (procedural stroke, major bleeding, device embolization, and pericardial effusion) was 7.4 events per 100 patient-years in the Watchman group compared with 4.4 events per 100 patient-years in the warfarin group (relative risk, 1.69). Pericardial effusions constituted $50 \%$ of the safety events in the Watchman group $(4.8 \%)$. Most safety events were early postprocedural, compared with the cumulative risk of warfarin therapy that would only increase with time. ${ }^{28}$

Unlike the earlier PLAATO system, the Watchman has a permeable covering membrane and thus requires $\mathrm{OAC}$ for at least 6 weeks until complete endothelialization is confirmed by TEE, followed by dual antiplatelet therapy (DAPT) for 6 months. The ASAP study was a single-armed prospective registry addressing this concern. A total of 150 patients with a mean $\mathrm{CHADS}_{2}$ score of 2.8 and contraindication to OAC were treated with the Watchman device and DAPT for life. The study was statistically underpowered and results were not definitive, but the numbers seemed to be lower than expected for $\mathrm{CHADS}_{2}$-matched individuals on only DAPT. ${ }^{29}$

Safety events were not the only concern regarding a percutaneous approach. The number of patients screened but not included in the trial (4291 candidates excluded of 4998 screened) raised questions about the external validity of the trial. Another concern was the detection of device thrombi by TEE in $4.8 \%$ of the Watchman group. In addition, more than $30 \%$ of patients enrolled in the PROTECT$\mathrm{AF}$ were found to have incomplete LAA closure at 12 months. Although disconcerting, a study of 389 of these patients concluded that residual peri-device flow was not associated with an increased risk of thromboembolism. ${ }^{30}$ This conclusion, however, is to be interpreted with caution given the small sample size and the low event rate.

Despite the initial safety concerns, a PROTECT-AF cohort of 707 patients was followed for a mean of 45 months and the safety equilibrated while efficacy changed from noninferior to superior. ${ }^{22}$ This is clearly because of the decreasing incidence of safety events in the Watchman group beyond the peri-procedural phase in conjunction with the incremental increase in risk over time with warfarin. The composite efficacy endpoint was also, for the first time, shown to be superior with the Watchman device (2.3 events per 100 patient-years) as compared with warfarin therapy (3.8 events per 100 patient-years) (hazard ratio $0.61,95 \%$ confidence interval $0.38-0.97 ; P=.035)$. Although ischemic strokes were still higher with the device, the more devastating hemorrhagic strokes were significantly reduced, and this was critical to the lower all-cause mortality in the device group. A more recent meta-analysis included 2406 patients from both the PROTECT-AF and subsequent PREVAIL trials and provided similar conclusions. ${ }^{31}$ This showed LAA occlusion to result in less overall cardiovascular/unexplained mortality ( 1.1 vs 2.3 events/100 patient-years; hazard ratio 0.48 ; $P=.006)$. The overall stroke rate was not significantly different, but there were more ischemic strokes with the device and more hemorrhagic strokes with warfarin. The Food and Drug Administration (FDA) initially did not grant approval to the Watchman because of concerns regarding early safety events (procedural stroke, major bleeding, device embolization, and pericardial effusion) and lack of clear evidence of benefit. After multiple rounds of controversy and the added data from the long-term follow-up, the FDA approved the Watchman device in March 2015 for use in patients with nonvalvular $A F$ with $\mathrm{CHA}_{2} \mathrm{DS}_{2}$-VASc score $\geq 2$, acknowledging that the benefits associated with the Watchman may outweigh its risks, especially in patients unsuitable for or not wanting lifelong $A C$.

\section{Amplatzer Cardiac Plug}

The Amplatzer cardiac plug (St Jude Medical, St Paul, Minn) is a self-expanding nitinol implant consisting of a lobe and a disc connected by a central waist. The lobe is larger than that with the Amplatzer septal occluder and has 6 stabilizing wires, and the disc seals the mouth of the LAA in a "pacifier"-like fashion (Figure 1). Like the early PLAATO, the Amplatzer plug does not require warfarin and, therefore, can be used in patients with contraindications to warfarin. In the early European experience, Park et $\mathrm{al}^{32}$ retrospectively evaluated procedural safety for up to 24 hours after implantation. Their review revealed significant safety concerns for the Amplatzer plug despite the procedures being performed by highly skilled operators. The Asia-Pacific experience demonstrated a better safety profile, and at a mean follow-up of 12 months, complete LAA occlusion was accomplished in $100 \%$ of patients. ${ }^{33}$

In terms of efficacy, Urena et $\mathrm{al}^{34}$ implanted the Amplatzer plug in 52 patients with a mean CHADS $_{2}$ score of 3 and contraindications to OAC. Despite incomplete LAA closure in $16 \%$ of patients at 6 months, the incidence of stroke was less than expected for matched $\mathrm{CHADS}_{2}$ scores at 20 months.

The largest experience is that of Tzikas et $\mathrm{al}^{35}$ from their report of 1047 patients treated with the Amplatzer device. They reported a $97.3 \%$ procedural success and $4.97 \%$ procedural-related adverse events. Major adverse events included death $(0.76 \%)$, stroke $(0.86 \%)$, device embolization $(0.77 \%)$, and major bleeding and cardiac tamponade $(1.24 \%$ each). Follow-up was completed for a mean of 13 months, and the annual rates of systemic thromboembolism and major bleeding were $2.3 \%$ and $2.1 \%$, respectively. 
These represented 59\% and $61 \%$ risk reductions compared with the expected rates. Bleeding complications were more commonly encountered in patients resumed on aspirin compared with those on no therapy. The Amplatzer device is currently not FDA approved. A further prospective randomized (2:1) trial is now enrolling patients with previous gastrointestinal bleeding of no treatable cause and a $\mathrm{CHA}_{2} \mathrm{DS}_{2}$-VASc score $\geq 3$ for either the Amplatzer plug or warfarin.

Additional endocardial LAA occlusion devices are in various stages of animal or early human trials. ${ }^{36-40}$

\section{EPICARDIAL LAA OCCLUSION DEVICES}

Epicardial LAA occlusion, although often more invasive, has several theoretical advantages: (1) avoiding a foreign body in contact with the blood stream that may be a nidus for thrombus or infection; (2) avoiding long-term, and often perioperative, anticoagulation; (3) avoiding LAA sizing and morphology concerns (except for the Lariat [SentreHEART, Palo Alto, Calif]); (4) consistent closure, with minimal residual LAA-to-left atrial leaks; and (5) lower device costs compared with the endocardial devices. Epicardial closure can be performed as an adjunct to concomitant cardiac procedures or as a stand-alone procedure. Stand-alone procedures are either surgical or percutaneous.

\section{With Concomitant Cardiac Surgery}

As previously mentioned, the ACC/AHA recommended exclusion of the LAA during surgical ablation of AF or mitral valve surgery in 2006. ${ }^{19}$ Many techniques have been described to close the LAA with variable results. Of the previously described techniques, endocardial suturing is perhaps the worst because there is a residual LAA-to-left atrial connection in more than half of the patients. Surgical excision of the LAA followed by a double-layered suture closure of the left atrial wall defect is superior to any other technique in terms of efficacy but requires the patient to be on cardiopulmonary bypass, preferably under cardioplegic arrest to prevent air embolism. External LAA closure using a stapling device is an effective way to close the LAA but leaves a residual "pouch" of greater than $1 \mathrm{~cm}$ at the base of the LAA in more than one-third of patients, and these pouches are thrombogenic. ${ }^{18,41}$ The stapler technique has the advantage of being suitable for off-pump or less-invasive heart surgery. Variation in epicardial clamps and energy devices have been described, and uniformly had a higher and a more consistent complete closure than endocardial sutures. ${ }^{42-44}$ As mentioned, the Watchman device demonstrated that LAA closure can potentially replace OAC. Confirmation of this message in a surgical population is being evaluated in the LAAOS III study. ${ }^{45}$ This study is randomizing 4700
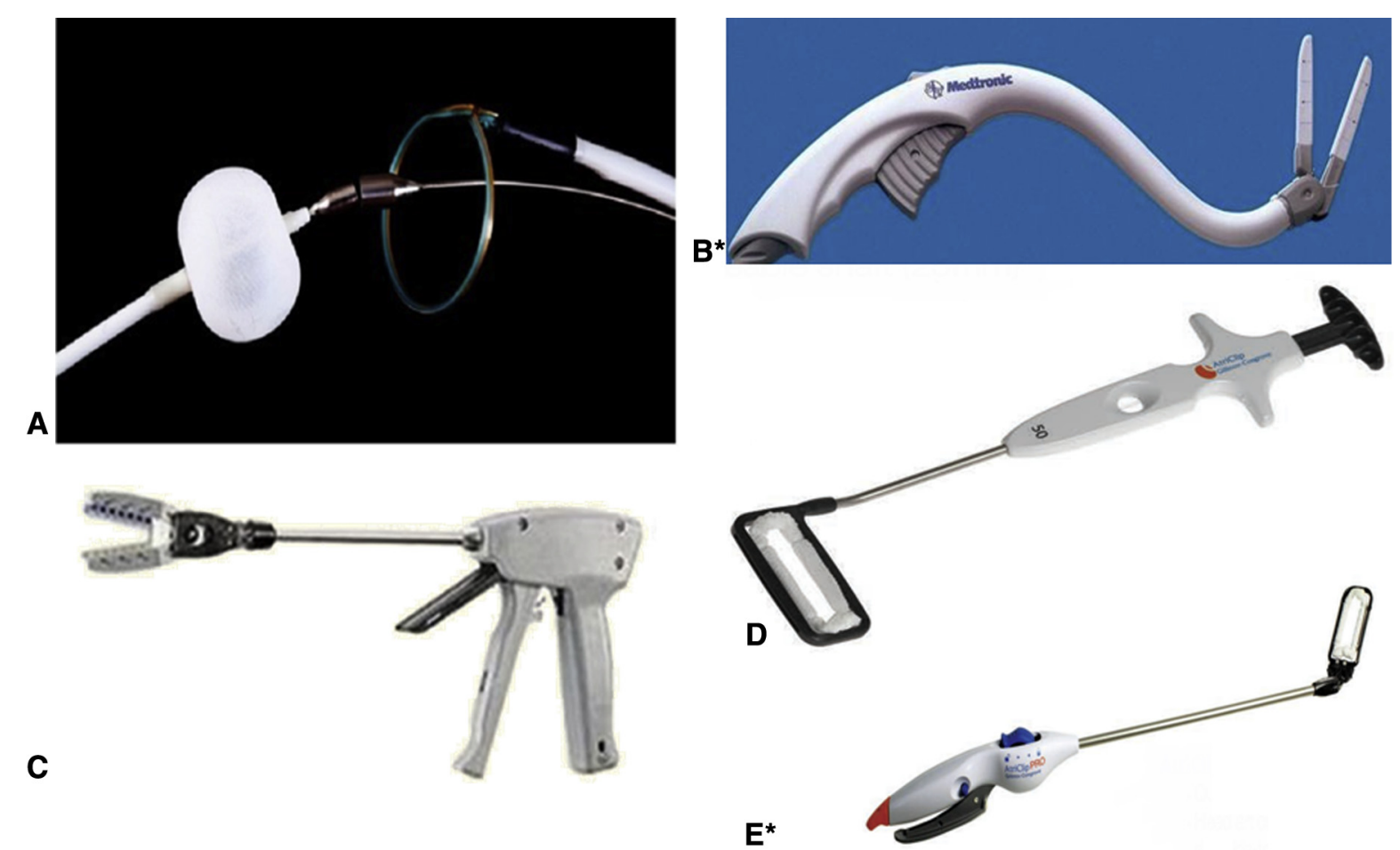

FIGURE 2. Epicardial left atrial appendage occluding devices. A, The Lariat suture delivery system. B, The Cardioblate occlusion device. *Currently not approved by the Food and Drug Administration. C, The TigerPaw system II. D, The Atriclip exclusion system (standard open approach). E, The Atriclip exclusion system (thoracoscopic approach). 
patients with $\mathrm{AF}$ undergoing on-pump procedures for ligation or nonligation of the LAA and is expected to be completed in 2016.

Two devices with nearly a $100 \%$ complete occlusion rate have been designed for LAA closure with concomitant cardiac procedures.

The TigerPaw II (Maquet Cardiovascular LLC, Wayne, NJ). This device consists of a fastener and a disposable delivery tool. The fastener is composed of linearly spaced connectors covered with soft silicone (Figure 2). The spacing allows it to conform to the anatomy of the LAA.

One clinical trial has been conducted and included 60 patients undergoing open cardiac surgery. ${ }^{46}$ One patient required repair of a tear site related to manual manipulation after fastener application. At 90 days, a complete occlusion rate of $100 \%$ was demonstrated in the 54 patients available for follow-up. The system was approved by the FDA for use with concomitant open cardiac procedures, but thus far, no stand-alone LAA closures using this device have been reported. Recently, the FDA issued a class I recall for the TigerPaw device due to increased safety concerns associated with bleeding and appendage tears.

The AtriClip (Atricure Inc, Westchester, Ohio). First, second, and third generations of this device were used in early animal studies in which no complications were reported and the occlusion rates at 90 days were consistently $100 \%{ }^{47-50}$ The AtriClip is made of 2 parallel straight titanium tubes with elastic nitinol springs covered by knit braided polyester to enhance fibrosis (Figure 2). The nitinol springs provide continuous dynamic pressure on each of the titanium tubes to enhance permanent closure of the LAA. The Atriclip can be used on a beating heart and the design allows redeployment in case of initial suboptimal placement. The device has been studied and approved for LAAE closure with concomitant cardiac procedures both in Europe and the United States. In 2009, the device achieved the CE mark after Salzberg et $\mathrm{al}^{51}$ demonstrated feasibility and safety on 34 patients undergoing cardiac surgery. These authors demonstrated safety with no devicerelated complications, and intraoperative TEE confirmed complete occlusion in $100 \%$ of the cases. Short-term efficacy was demonstrated after 3 months, confirming complete occlusion and Atriclip stability by computed tomography $(\mathrm{CT})$ in all patients.

In the United States, FDA approval of the AtriClip followed the EXCLUDE trial that enrolled 71 patients with $\mathrm{CHADS}_{2}$ score $>2$ undergoing open cardiac procedures in 7 US centers. In 1 patient, the LAA morphology was not suitable for clip application. The rate of complete exclusion was $95.7 \%$ by intraoperative TEE. After 3 months, there were no adverse events, and complete occlusion was confirmed by CT scan and TEE in $98.4 \%$ of the cases. ${ }^{52}$ Stand-alone LAA closure using the AtriClip also has been reported and currently a study for thoracoscopic AtriClip application completed recruiting patients with $\mathrm{CHADS}_{2}$ score $\geq 2$ and contraindication for OAC. The results are expected to provide a clearer understanding of the role of the AtriClip device in patients not undergoing cardiac surgery.

\section{Stand-Alone Epicardial LAA Occlusion}

Surgical epicardial LAA occlusion. The thoracoscopic approach to LAA occlusion was first reported by Blackshear et $\mathrm{al}^{53}$ using loop snares or a stapling device in $15 \mathrm{pa}$ tients with failed or contraindicated warfarin therapy, most of whom had suffered previous thromboembolic events. The procedure appeared safe and there was a statistical trend toward thromboembolic risk reduction. In a more recent study, Ohtsuka et al ${ }^{54}$ performed 30 stand-alone thoracoscopic LAA excisions using an endoscopic cutter. They included 21 patients with a mean $\mathrm{CHA}_{2} \mathrm{DS}_{2}$-VASc score of 4.5 and contraindications to warfarin. Feasibility and safety results were acceptable with a mean operative time of only 32 minutes, although 2 patients required minithoracotomies for dense pleura-pericardial adhesions. No major complications were encountered. At 3 months, complete LAA occlusion was confirmed by CT scan in $100 \%$ of patients. All OAC was discontinued and at 16 months no strokes or thromboembolic events were reported.

Devices for LAA epicardial LAA occlusion also have been developed. The earliest was the Cardioblate (Medtronic Inc, Minneapolis, Minn). The device was an expandable silicone band marked with radio-opaque clips. Animal studies reported successful thoracoscopic implantation with no complications and a $100 \%$ complete occlusion rate. ${ }^{55}$ Unfortunately, further stand-alone human implantation was not attempted after a study that was intended to enroll 60 patients undergoing an open cardiac procedure was discontinued after the first 40 patients because of high rates of residual communications between the left atrium and LAA.

The other device designed for surgical epicardial LAA closure is the AtriClip (Atricure Inc). The AtriClip seems to be more promising, and as previously mentioned, a feasibility study for thoracoscopic AtriClip application was initiated with excellent outcomes. Current plans exist for a larger pivotal trial based on FDA recommendations. Several other devices also have been developed for the same purpose, but are still in the developmental stage.

Percutaneous epicardial LAA occlusion. This involves the Lariat (SentreHEART). This system uses a unique technique that combines endocardial and epicardial approaches. The system is based on a percutaneous transseptal delivery of a magnet-tipped endocardial catheter that approximates transmurally to another epicardial magnet-tipped guidewire that is inserted via the pericardium. A previously tied radio- 
opaque suture is guided down the wire and tightened at the base of the LAA (Figure 2). The FDA approved the device on a $510 \mathrm{~K}$ after the demonstration of satisfactory results in 2 animal studies. ${ }^{56,57}$

The European experience with the Lariat was reported by Bartus et $\mathrm{al}^{58,59}$ in 2 consecutive studies. In the PLACE II study, 89 patients who were poor candidates for OAC and with a low risk for AF underwent closure of the LAA with a Lariat device. Three patients were excluded from the study due to pericardial adhesions. The authors reported a $96 \%$ procedural success after 1 case could not be completed because of pericardial adhesions, 1 case in which the transseptal puncture could not be performed, and 2 cases in which there were pericardial access complications. Patients with superior-posterior LAA orientation also were excluded from the study. Significant adverse events included 2 cardiac tamponades requiring drainage due to right ventricular (RV) puncture. Two patients experienced postprocedural pericarditis, one of which triggered a diagnostic coronary angiography. One patient had a late pericardial effusion. At 1 year, complete LAA closure was confirmed in $98 \%$ of patients, but 1 patient was found to have a thrombus in the left atrium. The efficacy of the Lariat itself for stroke prevention was difficult to determine because $55 \%$ of the patients were continued on warfarin.

The US experience with the Lariat device was reported by Massumi et $\mathrm{al}^{60}$ and Stone et al. ${ }^{61}$ The former study included 20 patients with a mean $\mathrm{CHADS}_{2}$ score of 3.2, including 15 patients with contraindications to OAC. They reported a procedural success of $100 \%$ and complete closure rate of $95 \%$. One patient had perforation of the RV that required open surgical repair and another patient experienced cardiac tamponade due to pericardial effusion requiring drainage. Three more patients presented shortly after the procedure with severe pericarditis requiring hospitalization, with 1 requiring drainage. At 3 months' follow-up, only 1 patient had persistent Doppler flow between the LA and the LAA. At a mean follow-up of 11.7 months, no strokes or thromboembolic events were reported. Stone et al $^{61}$ studied 27 patients with contraindications to OAC and a mean $\mathrm{CHADS}_{2}$ score of 3.5. Procedural success and completeness of LAA occlusion were $93 \%$ and $96 \%$, respectively. One patient experienced an LAA perforation requiring drainage and blood transfusion and eventually underwent a Maze procedure with LAA ligation

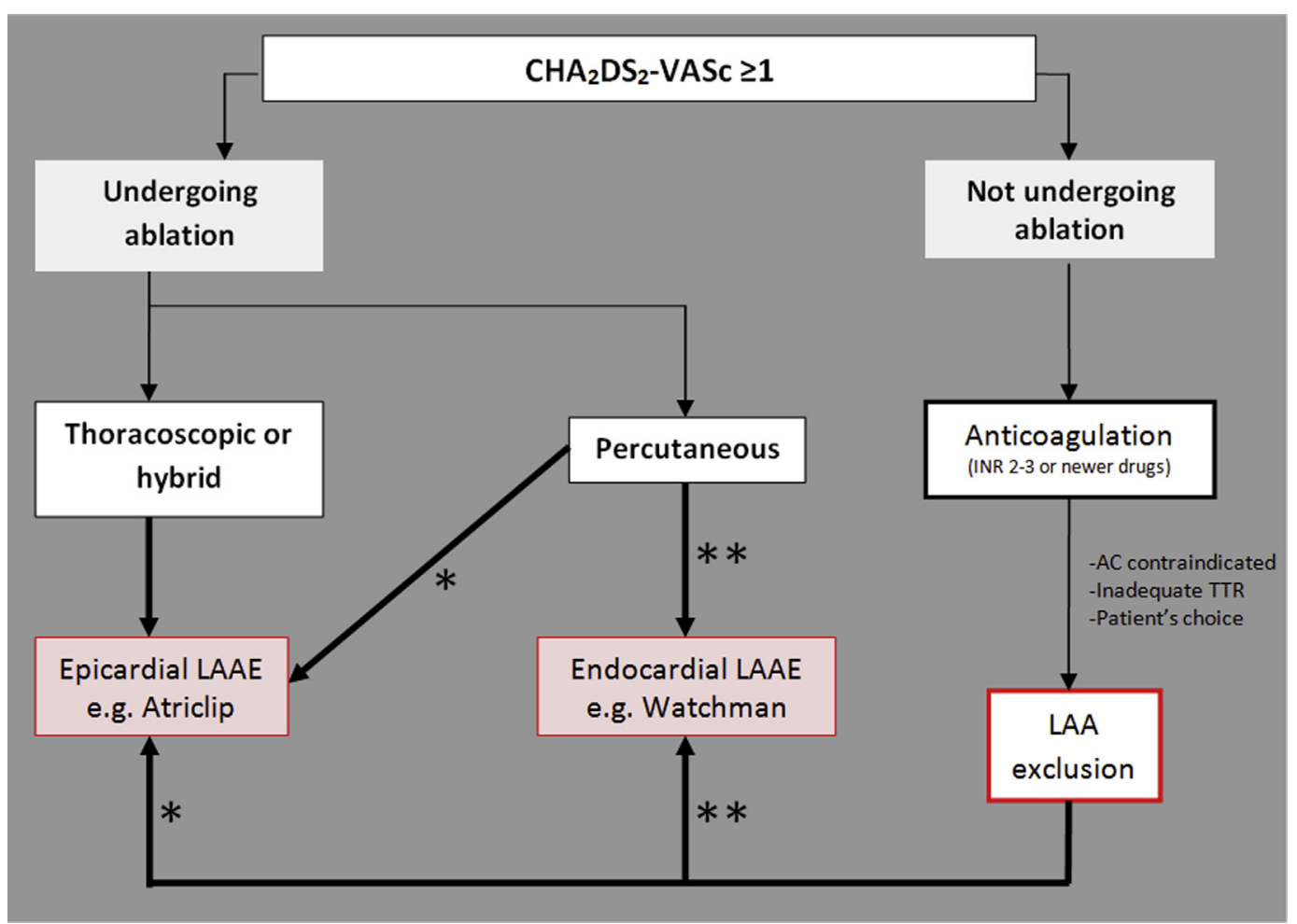

FIGURE 3. Proposed approach to stroke risk reduction in patients with atrial fibrillation not undergoing open cardiac procedures. *Preferred, with contraindications to anticoagulation or unfavorable left atrial appendage morphology. **Preferred with nonsurgical candidates and those with previous cardiac or left thoracic surgery. $\mathrm{CHA}_{2} \mathrm{DS} \mathrm{S}_{2}$-VASc, congestive heart failure, hypertension, age $>75$ and diabetes mellitus, previous history of stroke or transient ischemic attack, vascular disease, age 65-74 years, and female sex category; $A C$, anticoagulation, TTR, time in therapeutic range, $L A A$, left atrial appendage; $L A A E$, left atrial appendage exclusion. 


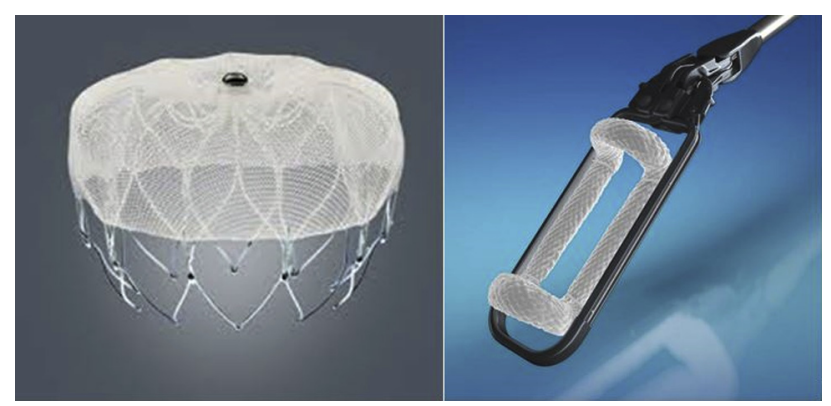

FIGURE 4. The Watchman endocardial left atrial occlusion device (left) and the AtriClip epicardial left atrial occlusion device (right).

the following day. Another patient suffered a procedural stroke related to thrombus from the transseptal sheath, and 3 patients had postprocedural pericarditis. At 1 month follow-up, 1 patient suffered a stroke believed to be aortic in origin. Forty-five days after the procedure, 100\% occlusion of the LAA was confirmed.

At least 3 cases have been reported with left atrial and/or LAA thrombus formation after Lariat application. ${ }^{57-59}$ Relatively high rates of $R V$ and LAA punctures and perforations often requiring drainage as well as procedure-related pericarditis/effusion are at many times of clinical consequences. For now, the FDA recently issued a safety communication regarding the Lariat: 45 adverse events were reported, $75 \%$ of which required emergent surgery and resulted in 6 mortalities. ${ }^{62}$ Meanwhile, SentreHEART reports that more than 3700 Lariat procedures have been performed in the United States since 2009 with a very good safety profile. More prospective data are needed.

\section{CONCLUSIONS}

Warfarin predisposes to bleeding, it is difficult in many patients to stabilize the dosage to keep the patients in the therapeutic range, and patient compliance is a problem with up to $50 \%$ of all patients discontinuing warfarin within 24 months of its initiation. ${ }^{63}$ In addition, warfarin therapy requires frequent blood tests throughout its therapy. This leaves patients with $\mathrm{AF}$ in search for a safer, more reliable, and more convenient alternative that is at least as good as warfarin. Newer ACs seem to provide some clinical benefits, including the lack of frequent blood test requirements. Unfortunately, even with NOACs, there is a substantial risk of bleeding, they often replace a once-daily warfarin dose with a twice-daily dose, and after 2 years of initiation, almost $25 \%$ of all patients discontinued them.

As a result of these problems with $\mathrm{OAC}$, the interest in mechanical LAA closure is increasing. A quality-of-life survey on a subset of 547 patients in the PROTECT-AF trial showed that patients who underwent LAA closure and were off warfarin were generally happier than those on warfarin. ${ }^{64} \mathrm{~A}$ major benefit of the PROTECT-AF trial is that for the first time the concept for mechanical LAA closure was proven. It is the first adequately powered RCT to prove the long-argued theory that LAA exclusion offers protection from stroke associated with AF. Although very promising, some unresolved issues exist. ${ }^{65}$ The efficacy of the Watchman device in patients who can tolerate neither initial AC nor DAPT is not known. Similarly, longer-term efficacy is yet to be better demonstrated and understood. Another potential concern exists as some patients with AF may have other noncardiac etiologies for ischemic strokes, which may be better addressed by AC than by LAAE. These concerns are valid, and the magnitude of which will be better understood over the following years. While we await more data about existing and upcoming LAA occlusion devices, our proposed strategy may be a viable option in selected patients as an alternative to OAC (Figures 3 and 4). We recommend reliable surgical epicardial LAA exclusion in all patients with AF undergoing open cardiac surgery or thoracoscopic ablation. We also recommend isolated procedures for surgical epicardial LAA exclusion in patients with AF failing AC or those with absolute contraindications to $\mathrm{AC}$, making them unable to tolerate the initial recommended $\mathrm{AC}$ period with an effective percutaneous technique. We make the same recommendation for patients with $\mathrm{AF}$ not preferring $\mathrm{AC}$ but who have an LAA morphology that is not favorable for percutaneous devices.

\section{Conflict of Interest Statement}

Dr Holmes is a consultant for Boston Scientific and the principal investigator in the PROTECT-AF trial for the Watchman device. Dr Cox is a consultant for Adagio Medical, Atricure, Clearflow, CorMatrix Cardiovascular, Harpoon Medical, PAVmed, SentreHEART, and PotentiaMED. Dr Ramlawi is a consultant for Sorin, Medtronic, and Atricure and the principal investigator in the Stroke Feasibility Trial for the AtriClip. Dr Bedeir has no conflicts of interest to disclose.

\section{References}

1. Go AS, Hylek EM, Phillips KA, Chang Y, Henault LE, Selby JV, et al. Prevalence of diagnosed atrial fibrillation in adults: national implications for rhythm management and stroke prevention: the anticoagulation and risk factors in atrial fibrillation (atria) study. JAMA. 2001;285:2370-5.

2. Stollberger C, Chnupa P, Abzieher C, Langer T, Finsterer J, Klem I, et al. Mortality and rate of stroke or embolism in atrial fibrillation during long-term follow-up in the embolism in left atrial thrombi (elat) study. Clin Cardiol. 2004;27:40-6.

3. Wolf PA, Abbott RD, Kannel WB. Atrial fibrillation as an independent risk factor for stroke: The Framingham study. Stroke. 1991;22:983-8.

4. Harrison MJ, Marshall J. Atrial fibrillation, tias and completed strokes. Stroke. 1984;15:441-2.

5. Lamassa M, Di Carlo A, Pracucci G, Basile AM, Trefoloni G, Vanni P, et al. Characteristics, outcome, and care of stroke associated with atrial fibrillation in europe: data from a multicenter multinational hospital-based registry (the European Community Stroke Project). Stroke. 2001;32:392-8. 
6. Rosendaal FR, Cannegieter SC, van der Meer FJ, Briet E. A method to determine the optimal intensity of oral anticoagulant therapy. Thromb Haemost. 1993;69: 236-9.

7. Stroke Prevention in Atrial Fibrillation Investigators. Adjusted-dose warfarin versus low-intensity, fixed-dose warfarin plus aspirin for high-risk patients with atrial fibrillation: Stroke Prevention in Atrial Fibrillation III randomised clinical trial. Lancet. 1996;348:633-8.

8. Pokorney SD, Simon DN, Thomas L, Gersh BJ, Hylek EM, Piccini JP, et al. Stability of international normalized ratios in patients taking long-term warfarin therapy. JAMA. 2016;316:661-3.

9. Bedeir K, Giugliano RP, Ramlawi B. Chronic anticoagulation in non-valvular atrial fibrillation: where things stand. Int J Cardiol. 2016;222:615-9.

10. Ruff CT, Giugliano RP, Braunwald E, Hoffman EB, Deenadayalu N, Ezekowitz MD, et al. Comparison of the efficacy and safety of new oral anticoagulants with warfarin in patients with atrial fibrillation: a meta-analysis of randomised trials. Lancet. 2014;383:955-62.

11. Blackshear JL, Odell JA. Appendage obliteration to reduce stroke in cardiac surgical patients with atrial fibrillation. Ann Thorac Surg. 1996;61:755-9.

12. Madden JL. Resection of the left auricular appendix; a prophylaxis for recurrent arterial emboli. JAMA. 1949;140:769-72.

13. Johnson WD, Ganjoo AK, Stone CD, Srivyas RC, Howard M. The left atrial appendage: our most lethal human attachment! Surgical implications. Eur J Cardiothorac Surg. 2000;17:718-22.

14. Garcia-Fernandez MA, Perez-David E, Quiles J, Peralta J, Garcia-Rojas I, Bermejo J, et al. Role of left atrial appendage obliteration in stroke reduction in patients with mitral valve prosthesis: a transesophageal echocardiographic study. J Am Coll Cardiol. 2003;42:1253-8.

15. Almahameed ST, Khan M, Zuzek RW, Juratli N, Belden WA, Asher CR, et al. Left atrial appendage exclusion and the risk of thromboembolic events following mitral valve surgery. J Cardiovasc Electrophysiol. 2007;18:364-6.

16. Bando K, Kobayashi J, Hirata M, Satoh T, Niwaya K, Tagusari O, et al. Early and late stroke after mitral valve replacement with a mechanical prosthesis: risk factor analysis of a 24-year experience. J Thorac Cardiovasc Surg. 2003;126: 358-64.

17. Katz ES, Tsiamtsiouris T, Applebaum RM, Schwartzbard A, Tunick PA, Kronzon I. Surgical left atrial appendage ligation is frequently incomplete: a transesophageal echocardiograhic study. J Am Coll Cardiol. 2000;36:468-71.

18. Kanderian AS, Gillinov AM, Pettersson GB, Blackstone E, Klein AL. Success of surgical left atrial appendage closure: assessment by transesophageal echocardiography. J Am Coll Cardiol. 2008;52:924-9.

19. Bonow RO, Carabello BA, Kanu C, de Leon AC Jr, Faxon DP, Freed MD, et al. ACC/AHA 2006 guidelines for the management of patients with valvular heart disease: a report of the American College of Cardiology/American Heart Association task force on practice guidelines (writing committee to revise the 1998 guidelines for the management of patients with valvular heart disease): developed in collaboration with the Society of Cardiovascular Anesthesiologists: endorsed by the Society for Cardiovascular Angiography and Interventions and the Society of Thoracic Surgeons. Circulation. 2006;114:e84-231.

20. Dawson AG, Asopa S, Dunning J. Should patients undergoing cardiac surgery with atrial fibrillation have left atrial appendage exclusion? Interact Cardiovasc Thorac Surg. 2010;10:306-11.

21. Chatterjee S, Alexander JC, Pearson PJ, Feldman T. Left atrial appendage occlusion: lessons learned from surgical and transcatheter experiences. Ann Thorac Surg. 2011;92:2283-92.

22. Reddy VY, Sievert H, Halperin J, Doshi SK, Buchbinder M, Neuzil P, et al. Percutaneous left atrial appendage closure vs warfarin for atrial fibrillation: a randomized clinical trial. JAMA. 2014;312:1988-98.

23. Ostermayer SH, Reisman M, Kramer PH, Matthews RV, Gray WA, Block PC, et al. Percutaneous left atrial appendage transcatheter occlusion (plaato system) to prevent stroke in high-risk patients with non-rheumatic atrial fibrillation: results from the international multi-center feasibility trials. J Am Coll Cardiol. 2005:46:9-14.

24. Block PC, Burstein S, Casale PN, Kramer PH, Teirstein P, Williams DO, et al. Percutaneous left atrial appendage occlusion for patients in atrial fibrillation suboptimal for warfarin therapy: 5-year results of the PLAATO (Percutaneous Left Atrial Appendage Transcatheter Occlusion) study. JACC Cardiovasc Interv. 2009;2:594-600.

25. Bayard YL, Omran H, Neuzil P, Thuesen L, Pichler M, Rowland E, et al PLAATO (percutaneous left atrial appendage transcatheter occlusion) for prevention of cardioembolic stroke in non-anticoagulation eligible atrial fibrillation patients: results from the European PLAATO Study. EuroIntervention. 2010;6: 220-6.

26. Holmes DR, Reddy VY, Turi ZG, Doshi SK, Sievert H, Buchbinder M, et al Percutaneous closure of the left atrial appendage versus warfarin therapy for prevention of stroke in patients with atrial fibrillation: a randomised non-inferiority trial. Lancet. 2009;374:534-42.

27. Reddy VY, Doshi SK, Sievert H, Buchbinder M, Neuzil P, Huber K, et al. Percutaneous left atrial appendage closure for stroke prophylaxis in patients with atria fibrillation: 2.3-year follow-up of the PROTECT AF (Watchman Left Atria Appendage System for Embolic Protection in Patients with Atrial Fibrillation) trial. Circulation. 2013;127:720-9.

28. Reddy VY, Holmes D, Doshi SK, Neuzil P, Kar S. Safety of percutaneous left atrial appendage closure: results from the Watchman Left Atrial Appendage System for Embolic Protection in Patients with AF (PROTECT AF) clinical trial and the continued access registry. Circulation. 2011;123:417-24.

29. Reddy VY, Mobius-Winkler S, Miller MA, Neuzil P, Schuler G, Wiebe J, et al. Left atrial appendage closure with the Watchman device in patients with a contraindication for oral anticoagulation: the ASAP study (ASA Plavix Feasibility Study with Watchman Left Atrial Appendage Closure Technology). J Am Coll Cardiol. 2013;61:2551-6.

30. Viles-Gonzalez JF, Kar S, Douglas P, Dukkipati S, Feldman T, Horton R, et al. The clinical impact of incomplete left atrial appendage closure with the watchman device in patients with atrial fibrillation: a PROTECT AF (percutaneous closure of the left atrial appendage versus warfarin therapy for prevention of stroke in patients with atrial fibrillation) substudy. J Am Coll Cardiol. 2012;59: 923-9.

31. Holmes DR Jr, Doshi SK, Kar S, Price MJ, Sanchez JM, Sievert H, et al. Left atrial appendage closure as an alternative to warfarin for stroke prevention in atrial fibrillation: a patient-level meta-analysis. J Am Coll Cardiol. 2015;65: 2614-23.

32. Park JW, Bethencourt A, Sievert H, Santoro G, Meier B, Walsh K, et al. Left atrial appendage closure with amplatzer cardiac plug in atrial fibrillation: initial European experience. Catheter Cardiovasc Interv. 2011;77:700-6.

33. Lam YY, Yip GW, Yu CM, Chan WW, Cheng BC, Yan BP, et al. Left atrial appendage closure with amplatzer cardiac plug for stroke prevention in atrial fibrillation: initial Asia-Pacific experience. Catheter Cardiovasc Interv. 2012; 79:794-800.

34. Urena M, Rodes-Cabau J, Freixa X, Saw J, Webb JG, Freeman M, et al. Percutaneous left atrial appendage closure with the amplatzer cardiac plug device in patients with nonvalvular atrial fibrillation and contraindications to anticoagulation therapy. J Am Coll Cardiol. 2013;62:96-102.

35. Tzikas A, Shakir S, Gafoor S, Omran H, Berti S, Santoro G, et al. Left atrial appendage occlusion for stroke prevention in atrial fibrillation: multicentre experience with the amplatzer cardiac plug. EuroIntervention. 2015;11:1170-9.

36. Toumanides S, Sideris EB, Agricola T, Moulopoulos S. Transcatheter patch oc clusion of the left atrial appendage using surgical adhesives in high-risk patients with atrial fibrillation. J Am Coll Cardiol. 2011;58:2236-40.

37. Cheng Y, Mcgregor J, Sommer R, et al. Safety and biocompatibility of the coherex wavecrest left atrial appendage occluder in a 30-day canine study. Presented at: Transcatheter Cardiovascular Therapeutics (TCT) 2012; October 22-26, 2012; Miami Beach, FL.

38. Cheng Y, Conditt G, Yi G, et al. First in-vivo evaluation of the ultrasept left atrial appendage closure device. Presented at: Transcatheter Cardiovascular Therapeutics (TCT) 2012; October 22-26, 2012; Miami Beach, FL.

39. Kanthan A, Looi KL, Mottram P, Harper R, Bittinger L, Alison JF. Percutaneous left atrial appendage closure using a PFO closure device. Heart Lung Circ. 2013; 22:784-5.

40. Lam YY. A new left atrial appendage occluder (lifetech lambre device) for stroke prevention in atrial fibrillation. Cardiovasc Revasc Med. 2013;14:134-6.

41. Healey JS, Crystal E, Lamy A, Teoh K, Semelhago L, Hohnloser SH, et al. Left Atrial Appendage Occlusion Study (LAAOS): results of a randomized controlled pilot study of left atrial appendage occlusion during coronary bypass surgery in patients at risk for stroke. Am Heart J. 2005;150:288-93.

42. Bakhtiary F, Kleine P, Martens S, Dzemali O, Dogan S, Keller H, et al. Simplified technique for surgical ligation of the left atrial appendage in high-risk patients. $J$ Thorac Cardiovasc Surg. 2008; 135:430-1.

43. Jayakar D, Gozo F, Gomez E, Carlos C. Use of tissue welding technology to obliterate left atrial appendage-novel use of ligasure. Interact Cardiovasc Thorac Surg. 2005;4:372-3. 
44. Roth P, Rahimi A, Boening A. The pericardium-reinforced technique of amputation of the left atrial appendage: quick, safe, and simple. Ann Thorac Surg. 2010; 90:e11-3.

45. Whitlock R, Healey J, Vincent J, Brady K, Teoh K, Royse A, et al. Rationale and design of the Left Atrial Appendage Occlusion Study (LAAOS) III. Ann Cardiothorac Surg. 2014;3:45-54.

46. Slater AD, Tatooles AJ, Coffey A, Pappas PS, Bresticker M, Greason K, et al. Prospective clinical study of a novel left atrial appendage occlusion device. Ann Thorac Surg. 2012;93:2035-8; discussion 2038-40.

47. Kamohara K, Fukamachi K, Ootaki Y, Akiyama M, Cingoz F, Ootaki C, et al. Evaluation of a novel device for left atrial appendage exclusion: the secondgeneration atrial exclusion device. J Thorac Cardiovasc Surg. 2006;132:340-6.

48. Fumoto H, Gillinov AM, Ootaki Y, Akiyama M, Saeed D, Horai T, et al. A novel device for left atrial appendage exclusion: The third-generation atrial exclusion device. J Thorac Cardiovasc Surg. 2008;136:1019-27.

49. Kamohara K, Fukamachi K, Ootaki Y, Akiyama M, Zahr F, Kopcak MW Jr, et al. A novel device for left atrial appendage exclusion. J Thorac Cardiovasc Surg. 2005; 130:1639-44.

50. Kamohara K, Popovic ZB, Daimon M, et al. Impact of left atrial appendage exclusion on left atrial function. J Thorac Cardiovasc Surg. 2007; 133:174-81.

51. Salzberg SP, Plass A, Emmert MY, Martin M, Ootaki Y, Akiyama M, et al. Left atrial appendage clip occlusion: early clinical results. J Thorac Cardiovasc Surg. 2010;139:1269-74.

52. Ailawadi G, Gerdisch MW, Harvey RL, Hooker RL, Damiano RJ Jr, Salamon T, et al. Exclusion of the left atrial appendage with a novel device: early results of a multicenter trial. J Thorac Cardiovasc Surg. 2011;142:1002-9. 1009.e1.

53. Blackshear JL, Johnson WD, Odell JA, Baker VS, Howard M, Pearce L, et al. Thoracoscopic extracardiac obliteration of the left atrial appendage for stroke risk reduction in atrial fibrillation. J Am Coll Cardiol. 2003;42:1249-52.

54. Ohtsuka T, Ninomiya M, Nonaka T, Hisagi M, Ota T, Mizutani T. Thoracoscopic stand-alone left atrial appendectomy for thromboembolism prevention in nonvalvular atrial fibrillation. J Am Coll Cardiol. 2013;62:103-7.

55. McCarthy PM, Lee R, Foley JL, Phillips L, Kanayinkal T, Francischelli DE. Occlusion of canine atrial appendage using an expandable silicone band. $J$ Thorac Cardiovasc Surg. 2010;140:885-9.
56. Singh SM, Dukkipati SR, d'Avila A, Doshi SK, Reddy VY. Percutaneous left atrial appendage closure with an epicardial suture ligation approach: a prospective randomized pre-clinical feasibility study. Heart Rhythm. 2010;7 370-6.

57. Lee RJ, Bartus K, Yakubov SJ. Catheter-based left atrial appendage (LAA) ligation for the prevention of embolic events arising from the LAA: initial experience in a canine model. Circ Cardiovasc Interv. 2010;3:224-9.

58. Bartus K, Bednarek J, Myc J, Kapelak B, Sadowski J, Lelakowski J, et al. Feasibility of closed-chest ligation of the left atrial appendage in humans. Heart Rhythm. 2011;8:188-93.

59. Bartus K, Han FT, Bednarek J, Myc J, Kapelak B, Sadowski J, et al Percutaneous left atrial appendage suture ligation using the lariat device in patients with atrial fibrillation: initial clinical experience. J Am Coll Cardiol. 2013;62:108-18

60. Massumi A, Chelu MG, Nazeri A, May SA, Afshar-Kharaghan H, Saeed M, et al Initial experience with a novel percutaneous left atrial appendage exclusion device in patients with atrial fibrillation, increased stroke risk, and contraindications to anticoagulation. Am J Cardiol. 2013;111:869-73.

61. Stone D, Byrne T, Pershad A. Early results with the lariat device for left atria appendage exclusion in patients with atrial fibrillation at high risk for stroke and anticoagulation. Catheter Cardiovasc Interv. 2015;86:121-7.

62. Food and Drug Administration. Use of LARIAT suture delivery device for left atrial appendage closure: FDA safety communication. Available at: http://www fda.gov/MedicalDevices/Safety/AlertsandNotices/ucm454501.htm. Accessed February 11, 2016

63. Connolly SJ, Ezekowitz MD, Yusuf S, Reddy V, Sievert H, Mullin C, et al. Dabigatran versus warfarin in patients with atrial fibrillation. $N$ Engl J Med. 2009;361:1139-51.

64. Alli O, Doshi S, Kar S, et al. Quality of life assessment in the randomized protect af (percutaneous closure of the left atrial appendage versus warfarin therapy for prevention of stroke in patients with atrial fibrillation) trial of patients at risk for stroke with nonvalvular atrial fibrillation. J Am Coll Cardiol. 2013;61: 1790-8.

65. Waks JW, Manning WJ. Left atrial appendage closure to reduce the risk of thromboembolic complications in atrial fibrillation: pay now and possibly pay later? J Am Coll Cardiol. 2015;65:2624-7. 